\title{
Evaluation of the Work-Integrated Learning Methodology: Teaching Marketing through Practitioner Experience in the Classroom
}

\author{
Luis-Alberto Casado-Aranda * ${ }^{\mathbb{D}}$, Juan Sánchez-Fernández $\mathbb{C}$, Francisco Javier Montoro-Ríos and \\ María Isabel Arias Horcajadas
}

Citation: Casado-Aranda, L.-A.; Sánchez-Fernández, J.; Montoro-Ríos, F.J.; Horcajadas, M.I.A. Evaluation of the Work-Integrated Learning Methodology: Teaching Marketing through Practitioner Experience in the Classroom. Mathematics 2021, 9 , 2164. https://doi.org/10.3390/ math9172164

Academic Editors: Aleksandra Gawel, Miloš S. Krstić and

Katarzyna Mroczek-Dąbrowska

Received: 6 August 2021

Accepted: 3 September 2021

Published: 5 September 2021

Publisher's Note: MDPI stays neutral with regard to jurisdictional claims in published maps and institutional affiliations.

Copyright: (c) 2021 by the authors. Licensee MDPI, Basel, Switzerland. This article is an open access article distributed under the terms and conditions of the Creative Commons Attribution (CC BY) license (https:// creativecommons.org/licenses/by/ $4.0 /)$.
Department of Marketing and Market Research, University of Granada, Campus Universitario Cartuja, 18011 Granada, Spain; sanchezf@ugr.es (J.S.-F.); fmontoro@ugr.es (F.J.M.-R.); miarias@ugr.es (M.I.A.H.)

* Correspondence: lcasado@ugr.es

\begin{abstract}
The teaching methodology in university marketing subjects has traditionally been based on "lecture classes", which have proved to be insufficient for providing students with professional skills that can be directly applied in the workplace. This research aims to reduce this gap between the university and business by applying the active teaching methodology of work-integrated learning (WIL), which consists of providing students with knowledge and experiences directly from professionals that are invited to the classroom. We evaluated the effects of the WIL methodology on university students in a marketing degree course through self-administered questionnaires. During a semester, perceived personal, academic, and professional outcomes were assessed in two groups of students of the same module, one of which participated in the WIL program (i.e., they received lectures by professional marketing experts who were invited to the classroom and explained, through real examples, the content of the subject being taught), and the other served as a control (i.e., they learned the content only through traditional lectures from the college instructor). The results revealed that the students who took part in the WIL program experienced increased motivation, enjoyment, and interest in the subject. Furthermore, they had an increased understanding and acquisition of the concepts, as well as a greater perceived ability to manage companies and a comprehension of the economic environment. These findings constitute an advance because they identify the benefits of applying WIL in knowledge fields where the acquisition of professional skills is crucial for graduates' entry into the labor market.
\end{abstract}

Keywords: work-integrated learning; marketing; professional experiences brought into the classroom; university; motivation; interest

\section{Introduction}

The lecture class methodology in the university context has been the primary mode of conveying information to large audiences since the beginning of history, and it remains the most common tool in university teaching to date. While this passive learning method has proven useful for quickly imparting basic knowledge to large classes of learners, it has certain limitations associated with the lack of interest, encouragement, attention, and managerial skills (such as problem-solving, interpersonal, teamwork, or analytical thinking) provided to students. These limitations are even more harmful in the field of university teaching of business and marketing, where teaching should have a direct and practical applicability to improve the labor market insertion of students.

The rapid increase in competitors in both the business world and business schools, the exponential growth of digitalization, and the need in the workplace for more practiceoriented graduates are forcing higher education institutions to offer teaching programs that are less focused on theoretically driven lectures and more on the practice and acquisition of professional skills. Along this line, the current research attempts to address for the 
first time the lack of research aimed at analyzing the benefits of applying a recent widely used active learning methodology, namely Work Integrated Learning (WIL henceforth), in undergraduate marketing courses. Specifically, this research assesses student's perceived outcomes resulting from the participation in the classroom of marketing practitioners invited to explain success stories and professional experiences. More particularly, the current research evaluates the ability of WIL programs to reduce the gap between universities and marketing workplaces, facilitate the incorporation of students into the professional world, and create a link between university teaching and professional training in marketing.

The findings of this article shed light on the effect of implementing the WIL methodology in the field of marketing knowledge and are crucial to highlight potential improvement on students' motivation, enjoyment, and knowledge acquisition, as well as their perceived ability to manage companies and solve economic and business problems.

\section{Materials and Methods}

\subsection{Literature Review}

\subsubsection{Traditional University Teaching}

The traditional instructional format of university teaching is defined as "...a lecturer's continuous presentation for approximately $80 \mathrm{~min}$ to a passive audience" (Butler, 1992). This "lecture class" methodology has been the primary mode of conveying information to large audiences since the beginning of history, and it remains the most common tool in university teaching to date [1]. This traditional tool is centered on the teacher, who offers theoretical information to the students on how to solve practical case studies with different alternatives and solutions [2]. Furthermore, instructors provide students with syllabi and class schedules, and they develop qualifications comprising a small number of assessment methods, which rely on multiple-choice, true-false, or theoretically driven questions [3]. The learner, in turn, passively receives this information and internalizes it through memorization.

While this passive learning method has proven useful for quickly imparting basic knowledge to large classes of learners [4], it has certain limitations. Research has shown that students do not remember much of the content after the theoretical sessions, do not pay enough attention, and do not acquire problem-solving, interpersonal, teamwork, or analytical thinking skills [5-7]. If the lecturer's purpose is to disseminate information about a specific discipline, then these lectures have proven to be highly effective (Bligh, 1972). However, if the college instructor's purpose is to go further and seek the acquisition of competences, skills, and attitude changes, these lectures have proven to be relatively ineffective due to the passive role played by the students (Bligh, 1972); [6].

In the specific area of business and marketing studies, teaching methodologies have traditionally been based on these lecture classes, as well as the support of graphic documentation (slides, videos, and photographs) to bring students closer to the reality of developing business strategies and making decisions. Despite attempts to complement these lecture classes with case studies, audio-visual material, and new assessment methodologies over the last 15 years, traditional teaching techniques have been found to be highly insufficient in the field of business and marketing [8]. The rapid increase in competitors in both the business world and business schools, the exponential growth of digitalization, and the need in the workplace for more practice-oriented graduates are forcing higher education institutions to offer teaching programs that are less focused on theoretically driven lectures and more on the practice and acquisition of professional skills [3]. Consequently, traditional passive tools need to be reshaped with the aim of addressing such new trends and fulfilling competences that are specified in current marketing curricula, such as encouraging entrepreneurship among students, the need for students to know and evaluate the market and the integrated environment within the marketing information system, the need for students to know how to apply their knowledge to their work or vocation in a professional manner, or the requirement for students to work in teams and develop intercommunicative skills in problem solving in their field of study. 


\subsubsection{A Call to Move from Passive to Active Learning Methodologies in Higher Education}

The new digital and professional context, together with the growing need to acquire practical skills, has encouraged universities around the world to gradually adapt to the marketplace's demand for professional skills related to leadership, decision making, critical thinking, and problem solving in graduates. In line with this trend, business schools currently aim to reduce the time spent delivering formal lectures while expanding the time that students spend on hands-on tasks and the development of analytical and decisionmaking competences [9]. Consequently, the new goal of higher education institutions is to move on from traditional passive tools to more active learning methodologies, which put college students at the center of the learning process while the instructors act as facilitators of professional knowledge, skills, and abilities. Some active learning methodologies include quizzes, classroom experiments, surveys, field trips to visit companies, role learning, business simulators, and internships, among others [10].

In response to these demands, new and diverse active learning methodologies have recently been introduced into the university environment, including the following:

(i) Problem-based learning. Here, students become the protagonists of a problem to be solved through the gradual acquisition of knowledge of a subject. It is a system that follows a scheme that is inverse to the traditional one: first, the problem is presented; then, the needed content is identified and the required information is sought; finally, the student returns to the problem [11].

(ii) Flipped classroom. This methodology requires that students prepare lessons outside the classroom and interact in the classroom to discuss ideas, participate in debates, or carry out group work using new technologies and the instructor's guide [12].

(iii) Participative learning. This methodology consists of giving the students the possibility to select the activities or parts of the assessment system of a subject. In this way, students feel responsible for the content learned and become more involved and motivated [13].

(iv) Role-playing. This methodology uses the spontaneous representation of a real or hypothetical situation with the aim of showing a problem or information that is relevant to the content of the course. Each student plays a role, but they can also exchange the roles that they play. In this way, they can approach the problem from different perspectives and understand different interpretations of the same reality. The participation of the students does not have to follow a specific script, but it is important to delimit and plan exercises prior to their implementation [14].

(v) Work-integrated learning (WIL). This is a teaching methodology that transfers theoretical concepts to students through professional classroom experience and practice. This conjunction between theory and work practice can take many forms, such as visits by industry experts to the classroom, simulation activities that involve students in the handling of practical equipment or methodologies, working with virtual patients or users in healthcare settings, or teaching internships [15].

The application of these active learning techniques has been shown to have strong positive effects on the learning process, competence acquisition, and student satisfaction. More specifically, research in the field of innovation in higher education shows that active methodologies improve student engagement and attention [16], the development of active learning, problem-solving skills, peer-learning, and critical thinking [17] and enhance knowledge retention, self-confidence, creativity, enjoyment, and attendance [18]. The use of these active tools in business and marketing has, in fact, improved students' innovation, decision-making skills, and confidence in working in a team and under pressure [19].

\subsection{Theoretical Fundamentals}

\subsubsection{WIL as an Emerging Active Learning Methodology}

While the above-mentioned learning tools have been used interchangeably in the university environment, the WIL methodology has been gaining interest over the last ten years because of its high and efficient ability to build a bridge between theory and 
practice [20]. Universities all over the world are increasingly making use of examples, case studies, and professional experiences in the classroom with the aim of training graduates for the challenges, decisions, and strategies of the professional world (so-called job-ready graduates) [21]. Ref. [22] explained that WIL involves a teaching experience that is conducted in a practical setting. Furthermore, ref. [23] defined WIL as a "set of approaches and strategies that integrate theory with work practice within a curriculum". Along the same lines, ref. [24] referred to participatory activities that fall under the umbrella of experiential learning. For WIL methodologies to be successful, studies have agreed that its implementation must [25]: (i) seriously engage with workplace practices and experiences, (ii) be embedded within an intentionally discipline-focused curriculum, and (iii) be accompanied by a focus on graduate learning outcomes and career pathways.

Research in the field of university education has created a classification of WIL practices according to whether the methodology is applied on campus, off campus, or in a mixed environment (Rowe et al., 2012): (i) On campus: includes activities such as panel sessions, role-playing games, simulation software competitions, visits from professional experts in the field of study, case studies, extracurricular activities, virtual projects, and interviews with entrepreneurs; (ii) off-campus: incorporates initiatives such as vocational work, company/factory/workplace visits, paid employment, community service, research or professional placements, internships, and volunteering; (iii) mixed environment: includes internships, tutorials, research projects, fieldwork, or group projects for external clients.

Investigations in the field of university education have largely evaluated the benefits of implementing WIL practices in the classroom. The following is a summary of the main personal, academic, and professional benefits to the student, as well as the benefits to industry, of participating in WIL sessions.

(i) Professional benefits. The literature has unanimously concluded that the connections and relationships with the work environment that students develop during WIL sessions (with peers, people, managers, work environment, organizational culture, etc.) provide them with a more direct and quicker entry into the labor market [26,27]. A significant advantage that these students have over non-WIL students is that they have evidence of their ability to apply their technical knowledge and skills in a real work environment, enabling them to develop more accurate and efficient decisionmaking skills in the near future.

(ii) Academic benefits. In addition to professional skills, being part of the WIL methodology brings pedagogical advantages during the learning process. For example, Fleming et al. (2018) concluded that WIL increases students' research skills, critical thinking, and time management skills. Other research has concluded that, after WIL sessions, students are more able to put theory into practice, improve their disciplined thinking, and increase analytical problem-solving skills under pressure [28]. In fact, after completing WIL sessions, it was confirmed that students were more motivated to continue with the theoretical and practical learning of a particular module. Other research even associated having taken part in WIL sessions with the achievement of higher grades (Tanaka, Y., and Carlson, 2012).

(iii) Personal benefits. Research in the field of university teaching has concluded that, after participating in WIL sessions, students improve their communication and interpersonal skills, decision-making abilities, and planning and organizational skills [15,29]. Other research has even concluded that students improve their job search confidence and empathy in line with the organizational culture of the company in question [30].

(iv) Benefits for industry. Companies that are part of WIL programs also benefit from the implementation of this teaching methodology. Firstly, students would be able to help with short-term, low-cost, and low-analytical-capacity tasks upon beginning [31]. In addition, involving students before graduation provides companies with the possibility to hire them and introduce fresh and different ideas (Rampersad and Jarvis, 2013). Many companies even establish links with universities to benefit from the technical and specialized knowledge of their students, as well as to access funding sources or 
collaborative projects that could improve their efficiency and business performance (Jackson et al., 2017).

(v) Benefits for universities. Employing WIL sessions in the classroom enables higher education institutions to provide full student immersion in professional practice related to their field of study by applying ad hoc professional standards and behaviors [32]. Furthermore, the WIL methodology facilitates a close collaboration between universities and industry, which can have an impact on updating the knowledge, skills, and competences that need to be included in undergraduate and postgraduate curricula.

\subsubsection{WIL as a Link between Universities and Business}

A large amount of the literature has already proven the above-mentioned positive effects of WIL on the learning process of university students in various fields of knowledge. For example, ref. [33] corroborated the higher effectiveness of professional-educational podcasts versus traditional lectures in teaching music and visual arts in higher education. Ref. [34] revealed that students who participated in WIL programs improved their final grades in nursing studies. Ref. [35] found that during the development and implementation of a "boutique" curriculum for the Queensland Health Workforce and Community Services Council, the WIL methodology provided students with more comprehensive learning and a measurable direct application of learning to the work environment. The study by Gentelli (2015) aimed to identify the psycho-pedagogical improvements in terms of outcomes, motivation, and student engagement as a result of implementing the WIL methodology in the field of forensic science. Their results revealed that the lectures given by professionals from the forensic industry were perceived as greatly important, attractive, and interesting for the students. The students recognized the importance of links between the university and industry, and appreciated the opportunity to learn from professional experts in the discipline in which they would work in the future. Along the same lines, a teaching innovation team led by Sánchez et al. (2010) transferred the classroom directly to the future workplace of technical architecture students. Their results revealed that both motivation and the acquisition of competences and results increased in students who underwent innovative teaching compared to those who did not.

Other studies have specifically corroborated the effects of WIL in the field of business administration and management. For example, Rambocas and Sastry (2017) evaluated the use of interactive business management lectures by engineering students. Their findings showed that WIL improved learning experiences and increased interest in the subject area. Ref. [36] further assessed the effectiveness of experiential learning to help college students explore the link between theory and practice. Their findings revealed higher cognitive and affective responses of students toward WIL methodologies. Ref. [37] reached similar conclusions in business operations management learning.

Although previous research has elucidated the role of WIL programs in teaching business management, no studies so far have corroborated the effects of the WIL active learning methodology on marketing students. Nonetheless, since marketing graduates will be responsible for co-creating value for customers, WIL methodologies would provide them with a first-hand experience prior to their professional career. Indeed, the recent study by [8] urged marketing students to co-create their educational experiences by actively participating in the decision-making processes of marketing companies while being enrolled in universities, receiving practical content from experts in the field, or simulating activities that require students to handle practical activities.

\subsubsection{The Study}

This study aims to address the lack of research aimed at analyzing the benefits of applying the WIL methodology in undergraduate marketing courses. Specifically, this research assesses student's perceived outcomes resulting from the participation in the classroom of marketing practitioners invited to explain success stories and professional experiences. 
Considering the personal benefits that the WIL technique could have for students participating in such a program (Crebert et al., 2004; Jackson, 2015; Drewery et al., 2020), we formally propose the following.

Hypothesis 1 (H1). Students who participate in the WIL program will report greater motivation for, interest in, and enjoyment of the marketing subject compared to those who receive traditional lectures.

In addition, based on the large number of studies that have demonstrated the academic and professional benefits of participating in WIL programs (Allen and Peach, 2011; Fleming et al., 2018; Papakonstantinou et al., 2013; Zegwaard and Coll, 2011), we hypothesize that:

Hypothesis 2 (H2). Students who participate in the WIL program will report higher levels of perceived knowledge acquisition and understanding of decision-making processes in professional marketing environments compared to those who receive traditional lectures.

This research evaluates the ability of WIL programs to reduce the gap between universities and marketing workplaces, facilitate the incorporation of students into the professional world, and create a link between university teaching and professional training in marketing.

\section{Results}

\subsection{The Developed Approach: Participants}

The present study used the WIL methodology for first-year undergraduates of the bachelor's degree in Business Administration and Management at the University of Granada. Specifically, 68 students (30 males, 38 females) averaging 18.6 years of age $(\mathrm{SD}=4.2$ years) studying the "Introduction to Marketing" subject participated in the WIL project. To evaluate the pedagogical contributions of WIL to the students' perceived outcomes, we compared them with the outcomes of a different group of 33 students (15 males, 18 females, averaging 18.4 years of age, $\mathrm{SD}=3.9$ years) of the same subject, in which the WIL methodology was not applied, but rather a more classical methodology with lectures. No significant differences in age or gender were found between the two comparison groups $(p<0.001)$.

The "Introduction to Marketing" subject provides the basic marketing knowledge needed to work in the different areas of commercial management, namely (i) the design of a marketing plan, (ii) the decision-making for product, price, communication, and distribution strategies, (iii) the development of SEO and SEM strategies, and (iv) the implementation of social marketing initiatives and political marketing analysis.

\subsection{The Steps of an Economic and Mathematical Model: Procedure and Design}

At the beginning of the term, the instructor presented the WIL experience and explained its usefulness and general objectives to the 68 students who participated in the WIL methodology. Two marketing professionals from the marketing departments of two international companies were invited to participate. The case studies and experiences to be explained in the classroom by the two professionals was coordinated with the instructor in order to cover the competences and contents of the subject. Simultaneously, the instructor developed the teaching material for the lectures to be given to the group of 38 students who did not participate in the WIL program.

Throughout the course, the instructor gave three lecture classes on the theoreticalpractical content to the students in the group without WIL, while the two marketing professionals explained, through their personal experiences and backgrounds, the same content in three sessions each, but approached it from their work/professional perspective. For instance, while the instructor explained the internal and external environmental factors that can affect companies to the 38 students who were not in the WIL program by means of theoretical texts and third-part examples, the two professionals explained to the 
68 WIL students how factors such as the COVID-19 crisis, the boom in online shopping, or government subsidies influenced their companies and decision making.

After the WIL and lecture-based sessions, students from both groups were required to fill out a self-administered questionnaire with the aim of assessing the perceived outcomes derived from the subject. Specifically, in relation to perceived outcomes, participants were asked about their level of motivation for, enjoyment of, and interest in the module using a seven-point Likert scale $(1=$ minimum level and $7=$ maximum level $)$ (following Jackson, 2015). In terms of professional outcomes, by means of a seven-point Likert scale $(1=$ minimum level and 7 = maximum level), we asked about the perceived level of acquisition of the competences set out in the subject's syllabus: (C1) level of understanding of the concepts, ideas, and, in general, the content of the subject; (C2) level of acquisition of knowledge of this module after completion of all seminars; (C3) level of the extent the activities proposed during all the lessons helped in learning; (C4) level of the ability to apply the knowledge of the subject to the professional environment; (C5) level of the ability to interpret relevant data related to this subject in order to make decisions; (C6) level of the ability to solve problems in business economics related to this subject; (C7) level of the ability to manage and administer a company considering the environment and competition; (C8) level of the ability to understand the economic reality and identify the roles of the environment and competition for the company. To identify significant differences in the perceived outcomes achieved by students with and without participation in the WIL program, Mann-Whitney tests were implemented with the IBM Statistical Package for the Social Sciences (IBM SPSS Version 20, Chicago, USA) software. We particularly implemented Mann-Whitney tests (non-parametric) because all Kolmogorov-Smirnov tests of the dependent variables showed non-normality in the data.

\subsection{The Case of the Model Implementation: Results}

With respect to the students' perceived outcomes after all sessions of the subject, the Mann-Whitney tests showed that those who participated in the WIL project were more motivated for the subject (mean $=5.66 ; \mathrm{SD}=1.06$ ) than those who did not take part in the methodology $($ mean $=4.24 ; \mathrm{SD}=1.56)(p<0.001)$. Furthermore, the WIL group showed significantly more interest in the subject's content (mean $=5.81 ; \mathrm{SD}=1.19)$ than the students who received lectures $($ mean $=4.97 ; \mathrm{SD}=1.21)(p=0.001)$. In addition, the students who experienced the WIL program reported greater levels of enjoyment (mean $=5.63 ; \mathrm{SD}=0.88$ ) than those who received lectures from the instructor $($ mean $=4.87 ; \mathrm{SD}=1.18)(p<0.001)$ (see Figure 1).

Finally, the students who participated in the WIL project not only showed significantly greater understanding of the concepts and acquisition of knowledge, but also expressed that they were better able to apply the acquired knowledge to the professional environment, interpret relevant data related to the syllabus, and use these data in decision making. More importantly, the students who participated in the WIL methodology expressed that they were more able to solve professional problems related to the subject's content, manage a company, and understand the economic reality in which companies operate. Additionally, we used correlation analyses to corroborate the extent to which increases in self-esteem of motivation, enjoyment, and interest in individual respondents correlated with high level of perceived knowledge. The results showed that the level of knowledge acquisition was significantly associated with perceived motivation $(\mathrm{r}=0.554 ; p<0.001)$, enjoyment $(\mathrm{r}=0.596 ; p<0.001)$, and interest $(\mathrm{r}=0.530 ; p<0.001)$. Table 1 shows the mean scores of each group for each skill and the significance associated with each Mann-Whitney test. 


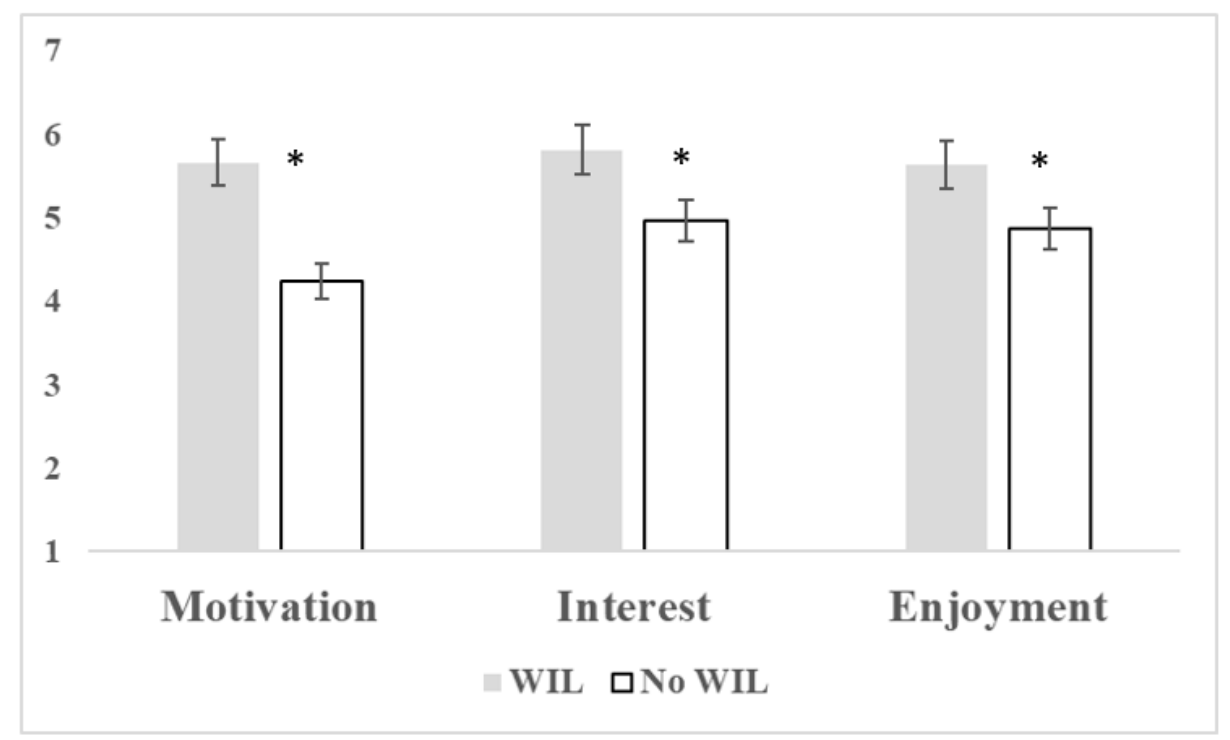

Figure 1. Graph showing the significant differences between the scores given by WIL participants and non-participants to motivation, interest, and enjoyment. $\left.{ }^{*}\right)$ means that the difference was significant.

Table 1. Average scores given by each group of students (WIL and non-WIL) to the learning competences of the subject Introduction to Marketing.

\begin{tabular}{|c|c|c|c|c|c|}
\hline \multirow{3}{*}{ Academic Outcome } & \multicolumn{4}{|c|}{ Students' Group } & \multirow{3}{*}{$p$ Value } \\
\hline & \multicolumn{2}{|c|}{ WIL } & \multicolumn{2}{|c|}{ Non-WIL } & \\
\hline & Mean & SD & Mean & SD & \\
\hline C1: Level of understanding of the concepts & 5.78 & 0.96 & 5.34 & 1.21 & 0.047 \\
\hline C2: Level of acquisition of knowledge & 5.54 & 0.99 & 4.92 & 1.23 & 0.012 \\
\hline $\begin{array}{l}\text { C3: Level of the extent the activities } \\
\text { proposed during all the lessons helped } \\
\text { in learning }\end{array}$ & 6.15 & 0.95 & 5.47 & 1.26 & 0.003 \\
\hline $\begin{array}{l}\text { C4: Level of the ability to apply the } \\
\text { knowledge of the subject to the } \\
\text { professional environment }\end{array}$ & 5.34 & 0.95 & 4.68 & 1.18 & 0.005 \\
\hline $\begin{array}{l}\text { C5: Level of the ability to interpret relevant } \\
\text { data related to this subject in order to } \\
\text { make decisions }\end{array}$ & 5.53 & 0.92 & 4.71 & 1.29 & 0.001 \\
\hline $\begin{array}{l}\text { C6: Level of the ability to solve problems in } \\
\text { business economics related to this subject }\end{array}$ & 5.28 & 0.97 & 4.45 & 1.30 & 0.002 \\
\hline $\begin{array}{l}\text { C7: level of the ability to manage and } \\
\text { administer a company considering the } \\
\text { environment and competition }\end{array}$ & 5.26 & 0.97 & 4.76 & 1.12 & 0.037 \\
\hline $\begin{array}{l}\text { C8: Level of the ability to understand the } \\
\text { economic reality and identify the roles of } \\
\text { the envi-ronment and competition for } \\
\text { the company }\end{array}$ & 5.65 & 0.92 & 4.82 & 1.27 & 0.001 \\
\hline
\end{tabular}

\section{Discussion}

This study constitutes the first evaluation of the improvements that the implementation of WIL entails in the perceived outcomes of students of a marketing subject. To this end, it compares the results of two groups of students-one that took part in a WIL methodology and one that received traditional lectures. In line with Hypothesis 1, the application of WIL in the field of marketing resulted in significantly more motivated students with a greater interest in and enjoyment of the content of the subject. These results are in line with 
the findings of previous research in other disciplines (Crebert et al., 2004; Drewery et al., 2020; Jackson, 2015) and confirm that the application of active learning techniques, such as WIL, leads to affective improvements in marketing students, which, ultimately, could be key in achieving more efficient acquisition and application knowledge with respect to the professional world.

On the other hand, in Hypothesis 2, we expected academic and professional improvements in the students who participated in the WIL methodology. Supporting this hypothesis, the results revealed that participants of the WIL program showed significantly greater levels of all academic (acquisition and understanding of knowledge) and professional competences (application of knowledge to professional settings, interpretation of relevant data for decision making, ability to manage a business, and understanding of economic reality). This result is key because, in line with the findings of previous studies in unrelated fields (Allen and Peach, 2011; Fleming et al., 2018; Papakonstantinou et al., 2013; Zegwaard and Coll, 2011), it has been proven that a university learning methodology alone can improve marketing students' perception of how to make good professional decisions and appropriately interpret data from the economic environment. In other words, talks by marketing experts in the classroom about their experiences and professional careers have proven to be efficient in bridging the professional and academic worlds based on the perspectives of marketing students. Interestingly, we showed by first time that increases in perceived knowledge acquisition are derived from the higher motivation, enjoyment, and interest of students that participated in the WIL program.

Theoretically, these results advance the line of research exploring the benefits of active versus traditional learning techniques in higher education. For example, previous research has analyzed the added value of innovative methodologies, such as the flipped classroom [38,39], role playing [40], or participative learning, over traditional lectures [41]. The current research constitutes a step forward in that regard, as it identifies the benefits of applying WIL in knowledge fields (such as marketing) where the acquisition of professional skills and competences is crucial for graduates' entry into the labor market. Specifically, we conclude that the use of professional marketing experts in university classrooms improves students' confidence in their ability to manage companies and solve economic and business problems. In addition, we show that the WIL methodology can make a difference in increasing students' motivation and ability to apply knowledge in the marketplace. Therefore, if the traditional lectures in teaching units were complemented by the presence of professional experts, then the disconnect between the professional world and marketing/business students would be reduced.

Future research should evaluate the presence of professional experts in the classroom in not only three teaching sessions, but in each of the teaching units of the subject. In addition, improvements in the grades or objective external tests of skill acquisition of the students who participate in WIL could be implemented in further research in comparison to the grades of those who receive traditional lectures. More importantly, future researchers are in a good position to evaluate the improvements or advantages perceived by both the marketing industry and universities after the application of WIL programs in order to identify the overall effects of the application of the WIL methodology in the university classroom. In addition, prospective studies could assess the joint application of various active methodologies (e.g., WIL and flipped classroom) in fields such as marketing or business management. In their book "Professionalism in Mental Healthcare: Experts, Expertise and Expectations", Bhugra and Malik [42] confirmed that the upper personal skills and tactful charisma of experts (in the field of healthcare, in this case) have the ability to increase students' motivation and interest in the specific subject. Even though we did not measure the relationship between personal skills of professionals and students' outcomes, it could constitute a fruitful avenue for further research. 


\section{Conclusions}

The digitalization of the university learning process, coupled with the increased demands of the labor market for the acquisition of professional competences, has recently required higher education institutions to change their traditional teaching approaches. Traditional learning methodologies in which students are passive users of content have given way to active tools, in which the learners are at the center of the content learning process by means of innovative approaches, such as problem-based learning, flipped classrooms, participative learning, role-playing, and WIL [38]. In particular, WIL methodology has become the most widely applied in recent years, as it efficiently assures that students develop the ability to integrate their learning through a combination of academic and professional activities. In many disciplines, this active teaching methodology is reflected in university-industry collaborations, as professionals in a specific field complement theoretical lectures with success or failure cases, decisions, and dilemmas that are explained to the students in the classroom.

Although the literature on innovative higher education has evaluated WIL experiences in the health, forensic science, music, architecture/engineering, and even business management fields, the effect of implementing the WIL methodology in the field of marketing has not been analyzed to date. The application of the WIL methodology has become even more urgent in marketing curricula due to the need to strengthen the link between universities and marketing, as well as the need to train future marketing managers who are able to co-create value for customers by means of problem-solving, analytical, reflective, business decision-making experiences, or the digitalization in trade $[8,43]$.

The results of the current research shed light on the effect of implementing the WIL methodology in the field of marketing knowledge. Specifically, they show that the implementation of the WIL methodology improves students' motivation, enjoyment, and knowledge acquisition, as well as their perceived ability to manage companies and solve economic and business problems.

Author Contributions: Conceptualization, L.-A.C.-A. and M.I.A.H.; methodology, L.-A.C.-A. software, L.-A.C.-A. validation, L.-A.C.-A. and M.I.A.H.; formal analysis, L.-A.C.-A. and J.S.-F.; resources, J.S.-F., L.-A.C.-A., F.J.M.-R., and M.I.A.H.; data curation, L.-A.C.-A. writing-review and editing, L.-A.C.-A., J.S.-F., and F.J.M.-R. supervision, J.S.-F. and F.J.M.-R. All authors have read and agreed to the published version of the manuscript.

Funding: This study was supported by an Excellence Project award from the Junta de Andalusia [REF: B-SEJ-220-UGR18] and by a grant from the Fundación Ramón Areces [CISP18A6208]. In addition, it received support from the Teaching Innovation Project PIBD Basic I of the UGR (No. 20-45): Work-integrated learning: Enseñanza del marketing a través de la experiencia de profesionales llevada al aula.

Institutional Review Board Statement: The study was conducted according to the guidelines of the Declaration of Helsinki, and approved by the Ethics Committee of University of Granada (code 1824).

Informed Consent Statement: Informed consent was obtained from all subjects involved in the study.

Data Availability Statement: Data will be offered upon request.

Conflicts of Interest: The authors declare no conflict of interest.

\section{References}

1. Gentelli, L. Using Industry Professionals in Undergraduate Teaching: Effects on Student Learning. J. Univ. Teach. Learn. Pract. 2015, 12, 4 .

2. Zabit, M.N.M. Problem-Based Learning On Students Critical Thinking Skills In Teaching Business Education In Malaysia: A Literature Review. Asian J. Bus. Ethics 2010, 3, 19-32. [CrossRef]

3. Michel, N.; Cater, J.J.; Varela, O. Active versus Passive Teaching Styles: An Empirical Study of Student Learning Outcomes. Hum. Resour. Dev. Q. 2009, 20,397-418. [CrossRef]

4. Whetten, D.A.; Clark, S.C. An Integrated Model for Teaching Management Skills. J. Manag. Educ. 1996, 20, 152-181. [CrossRef]

5. Fadol, Y.; Aldamen, H.; Saadullah, S. A Comparative Analysis of Flipped, Online and Traditional Teaching: A Case of Female Middle Eastern Management Students. Int. J. Manag. Educ. 2018, 16, 266-280. [CrossRef] 
6. Raja, F.U. Najmonnisa Comparing Traditional Teaching Method and Experiential Teaching Method Using Experimental Research. J. Educ. Educ. Dev. 2018, 5, 276-288. [CrossRef]

7. Wingfield, S.S.; Black, G.S. Active Versus Passive Course Designs: The Impact on Student Outcomes. J. Educ. Bus. 2005, 81, 119-123. [CrossRef]

8. Smørvik, K.K.; Vespestad, M.K. Bridging Marketing and Higher Education: Resource Integration, Co-Creation and Student Learning. J. Mark. High. Educ. 2020, 30, 256-270. [CrossRef]

9. Prelims. Active Learning Strategies in Higher Education; Misseyanni, A.D., Lytras, M., Papadopoulou, P., Marouli, C., Eds.; Emerald Publishing Limited: Bingley, UK, 2018; pp. i-xxi. ISBN 978-1-78714-488-0.

10. Auster, E.R.; Wylie, K.K. Creating Active Learning in the Classroom: A Systematic Approach. J. Manag. Educ. 2006, 30, 333-353. [CrossRef]

11. Csapó, B.; Molnár, G. Potential for Assessing Dynamic Problem-Solving at the Beginning of Higher Education Studies. Front. Psychol. 2017, 8, 2022. [CrossRef]

12. Kay, R.; MacDonald, T.; DiGiuseppe, M. A Comparison of Lecture-Based, Active, and Flipped Classroom Teaching Approaches in Higher Education. J. Comput High. Educ. 2019, 31, 449-471. [CrossRef]

13. Liu, C.-C.; Chen, W.-C.; Lin, H.-M.; Huang, Y.-Y. A Remix-Oriented Approach to Promoting Student Engagement in a Long-Term Participatory Learning Program. Comput. Educ. 2017, 110, 1-15. [CrossRef]

14. Barrera, F.; Venegas-Muggli, J.I.; Nuñez, O. The Impact of Role-Playing Simulation Activities on Higher Education Students' Academic Results. Innov. Educ. Teach. Int. 2020, 58, 305-315. [CrossRef]

15. Jackson, D. Employability Skill Development in Work-Integrated Learning: Barriers and Best Practice. Stud. High. Educ. 2015, 40, 350-367. [CrossRef]

16. Hyun, J.; Ediger, R.; Lee, D. Students' Satisfaction on Their Learning Process in Active Learning and Traditional Classrooms. Int. J. Teach. Learn. High. Educ. 2017, 29, 108-118.

17. Vlachopoulos, D.; Makri, A. The Effect of Games and Simulations on Higher Education: A Systematic Literature Review. Int. J. Educ. Technol. High. Educ. 2017, 14, 22. [CrossRef]

18. Akçayır, G.; Akçayır, M. The Flipped Classroom: A Review of Its Advantages and Challenges. Comput. Educ. 2018, 126, 334-345. [CrossRef]

19. Keinänen, M.; Ursin, J.; Nissinen, K. How to Measure Students' Innovation Competences in Higher Education: Evaluation of an Assessment Tool in Authentic Learning Environments. Stud. Educ. Eval. 2018, 58, 30-36. [CrossRef]

20. Venville, A.; Lynch, B.; Santhanam, E. A Systematic Approach to the Evaluation of the Student Experience in Work-Integrated Learning. Int. J. Work. -Integr. Learn. 2018, 19, 13-21.

21. Harman, K.M. Producing 'Industry-ready' Doctorates: Australian Cooperative Research Centre Approaches to Doctoral Education. Stud. Contin. Educ. 2004, 26, 387-404. [CrossRef]

22. Cooper, L.; Orrell, J.; Bowden, M. Work Integrated Learning: A Guide to Effective Practice; Routledge: Abingdon, UK, 2010; ISBN 978-1-136-99103-5.

23. Patrick, C.; Peach, D.; Pocknee, C.; Webb, F.; Fletcher, M.; Pretto, G. The WIL (Work Integrated Learning) Report: A National Scoping Study [Final Report]; Queensland University of Technology: Brisbane, Australia, 2008; ISBN 978-1-74107-254-9.

24. Rowe, A.; Winchester-Seeto, T.; Mackaway, J. That's Not. Really WIL!-Building a Typology of WIL. In Proceedings of the Collaborative Education: Investing in the Future-Proceedings of the 2012 ACEN National Conference, Geelong, Australia, 29 October-2 November 2012.

25. Fleming, J.; McLachlan, K.; Pretti, T.J. Successful Work-Integrated Learning Relationships: A Framework for Sustainability. Int. J. Work. -Integr. Learn. 2018, 19, 321-335.

26. Papakonstantinou, T.; Charlton-Robb, K.; Reina, R.D.; Rayner, G. Providing Research-Focused Work-Integrated Learning for High Achieving Science Undergraduates. Asia-Pac. J. Coop. Educ. 2013, 14, 59-73.

27. Zegwaard, K.E.; Coll, R.K. Using Cooperative Education and Work-Integrated Education to Provide Career Clarification. Sci. Educ. Int. 2011, 22, 282-291.

28. Allen, J.M.; Peach, D. Assessing for Work Integrated Learning Experiences: A Pre-Service Teacher Perspective. Asia-Pac. J. Coop. Educ. 2011, 12, 1-17.

29. Crebert, G.; Bates, M.; Bell, B.; Patrick, C.-J.; Cragnolini, V. Developing Generic Skills at University, during Work Placement and in Employment: Graduates' Perceptions. High. Educ. Res. Dev. 2004, 23, 147-165. [CrossRef]

30. Drewery, D.W.; Pretti, T.J.; Church, D. Signaling 'Student-Oriented' Job Opportunities Enhances Job Attractiveness in WorkIntegrated Learning Programs. High. Educ. Res. Dev. 2020, 40, 1-14. [CrossRef]

31. Jackson, D.; Wilton, N. Developing Career Management Competencies among Undergraduates and the Role of Work-Integrated Learning. J. Mark. High. Educ. 2016, 21, 266-286. [CrossRef]

32. Doolan, M.; Piggott, B.; Chapman, S.; Rycroft, P. The Benefits and Challenges of Embedding Work Integrated Learning: A Case Study in a University Education Degree Program. Aust. J. Teach. Educ. 2019, 44, 91-108. [CrossRef]

33. Tam, C.O. The Effectiveness of Educational Podcasts for Teaching Music and Visual Arts in Higher Education. Res. Learn. Technol. 2012, 20. [CrossRef]

34. Geist, M.J.; Larimore, D.; Rawiszer, H.; Sager, A.W.A. Flipped Versus Traditional Instruction and Achievement in a Baccalaureate Nursing Pharmacology Course. Nurs. Educ. Perspect. 2015, 36, 114-115. [CrossRef] [PubMed] 
35. Choy, S.; Delahaye, B. University-industry partnership for pedagogy: Some principles for practice. In Proceedings of the 16th World Conference on Cooperative Education and World Integrated Learning; Hansford, M., Ed.; World Association for Cooperative Education: Lowell, MA, USA, 2009; pp. 1-10.

36. Chavan, M. Higher Education Students' Attitudes Towards Experiential Learning in International Business. J. Teach. Int. Bus. 2011, 22, 126-143. [CrossRef]

37. Penn, M.L.; Currie, C.S.M.; Hoad, K.A.; O’Brien, F.A. The Use of Case Studies in OR Teaching. High. Educ. Pedagog. 2016, 1, 16-25. [CrossRef]

38. Sailer, M.; Schultz-Pernice, F.; Fischer, F. Contextual Facilitators for Learning Activities Involving Technology in Higher Education: The Cb-Model. Comput. Hum. Behav. 2021, 121, 106794. [CrossRef]

39. O'Flaherty, J.; Phillips, C. The Use of Flipped Classrooms in Higher Education: A Scoping Review. Internet High. Educ. 2015, 25, 85-95. [CrossRef]

40. Moreno-Guerrero, A.-J.; Rodríguez-Jiménez, C.; Gómez-García, G.; Ramos Navas-Parejo, M. Educational Innovation in Higher Education: Use of Role Playing and Educational Video in Future Teachers' Training. Sustainability 2020, 12, 2558. [CrossRef]

41. Mareca, M.P.; Bordel, B. The Educative Model Is Changing: Toward a Student Participative Learning Framework 3.0—Editing Wikipedia in the Higher Education. Univ. Access Inf. Soc. 2019, 18, 689-701. [CrossRef]

42. Bhugra, D.; Malik, A. Professionalism in Mental Healthcare: Experts, Expertise and Expectations; Cambridge University Press: Cambridge, UK, 2010.

43. Barykin, S.Y.; Kapustina, I.V.; Sergeev, S.M.; Kalinina, O.V.; Vilken, V.V.; de la Poza, E.; Putikhin, Y.Y.; Volkova, L.V. Developing the physical distribution digital twin model within the trade network. Acad. Strateg. Manag. J. 2021, 20, 1-18. 